\title{
A Six Month Intervention Study on Strength Training in Youth Basketball Player in Albania
}

\author{
Spahi A. \\ Bilali A. \\ Jarani J.* \\ Sports University of Tirana, Street Muhamet Gjollesha, Tirana, Albania \\ *Corresponding Author Email: andispahi@gmail.com
}

\section{Doi:10.5901/ajis.2015.v4n2p319}

\begin{abstract}
Introduction. The literature concerning the physical preparation for youth basketball players is huge, although the literature concerning basketball strength training is still scare. The aims of this study were; to assess basketball fitness abilities before (PRE) and after (POST) a 6-month fitness training in youth basketball players (twice weekly); to show if there is any statistically improvement on physical fitness parameters after the intervention. Methods. Twenty-eight youth (male) basketball players (age range 17-18 years) participated in this intervention study. They were assessed PRE and POST training through the basketball strength test (izokinetic and izometric dynamometer) tests. The intervention study lasted 6 months (twice weekly) on a fitness gym (strength training). The duration for each training set had lasted for each $45 \mathrm{~min}$ (8 fitness machines was used). Results. Regarding physical components after the intervention data show a significant improvement in strength ( $p=0.001)$ for isometric and izokinetic performance on youth basketball players. No significant difference was observed for right foot during izokinetic performance $(p>0.05)$. Conclusion. In conclusion, it was found that the fitness training twice weekly could be useful for improving and monitoring physical parameters with regards to strength in youth basketball players.
\end{abstract}

Keywords: youth, basketball, training, strength

\section{Introduction}

The literature concerning the physical preparation is huge, although the literature concerning basketball strength training in youth is still scare (Jarani et al., 2014; Jarani et al., 2015). Different estimating techniques are known in order to define muscle coercion, endurance, and speed. For this purpose the actual study performed in youth basketball players is based on isometric, constant charge variable velocity exercise, and isokinetic activity (Alexander et al., 1973; Ellfeldf et al., 1986; Knapik et al., 1980; Walmsley, 1996). Mostly in recent years, for the reckoning of the muscle force are used the isokinetic dynamometers, which ensures a steady angular speed over the complete range of motion. Referring to the outcome of the study, when we take a professional basketball athlete who joins in a systematic training program, there is no reason in differentiating prevalent and non prevalent limb, because the workout phase does not lead to such conditions. Other researchers have come to such results too (Bandy et al, 1994; Mohtadi et al., 1990) in examples of normal populations (non-athletes). Strength training increases to the team of individual's value by growing motor skills for more efficient movement and enrich multi directional force implementation for greater sprint speed, higher jump heights, more explosive changes direction. Yet remains to be defined precisely the outcome of a systematic training program on professional basketball athletes or the extent of their physiological state. Particularly, when the required measurements were likely made by the managers of the team, who were not able to acquire a certain degree of scientific such as the isokinetic instruments could provide. There are two methods to measure strength; manual muscle testing and Isokinetic testing. Isokinetic testing is of greater used in laboratory testing using izokinetics equipment and it is of greater benefit of objective measurement, but there is debate about the protocols used expsacially the speed (Keasays et al., 2000). Isokinetic strength testing provides an objective means of quantifying existing levels of muscular strength (Nicholas, 1989).

The aims of this study were; to assess basketball fitness abilities before (PRE) and after (POST) a 6-month fitness training in youth basketball players (twice weekly); to show if there is any statistically improvement on physical fitness parameters after the intervention. 


\section{Methods}

Twenty-eight youth (male) basketball players (age range 17-18 years) participated in this intervention study. They were assessed PRE and POST training through the basketball strength test (izokinetic and izometric dynamometer) tests. The players came from two team that take place regularly in national basketball championship for youth. The teams were chosen randomly for a pool of 12 teams. The intervention study lasted 6 months (twice weekly) on a fitness gym (strength training). The duration for each training set had lasted for each 45 min (8 fitness machines was used). Informed consent was obtained from coaches and parent,

\section{Measurement}

\subsection{Dynamometric Analysis}

The strength of lower-limb was measured with Easy Tech Izometric Machine in the biomechanical laboratory in Sports University of Tirana (Albania). The youth basketball players who underwent this test were positioned on the examination chair following the instructions in the manual. Their hips were placed in 90 of flexion, with their thighs and the trunk secured by straps.

\subsection{Test Protocol}

The tests were made on extension and flexion of the knee. A preliminary bout of isokinetic measurement was made for each athlete to become familiar with the testing procedure.

After calibration, adjustments of the various subject positions and gravity compensation were made. The different tests were initially made for every limb separately with concentric practice. The selection of the leg that was examined first (dominant or nondominant) was made randomly. We followed the previously described definition of limb dominance.

A pretest performance on the isokinetic device took place with 10 repetitions. The preliminary test included 2 submaximal and 1 maximal repetition at each velocity.

The following parameters were measured for every athlete at 2 different velocities for each limb: (a) peak torque of the knee flexors and extensors during isometric and izokinetic movement, (b) average peak torque of the knee flexors and extensors during isometric and izokinetic movement.

\subsection{Intervention}

The Intervention on youth basketball players lasted for 6 months. The total frequency was twice weekly with a duration per session $45 \mathrm{~min}$. The training intervention was performed on the fitness gym (strength training) placed in the gym of Sports University of Tirana. Strength exercise was performed using 8 machines while the agility exercises (speed and agility exercises) were lasted with duration 10- 15 min (4-6 exercises).

\subsection{Statistical Analysis}

The data were gathered and organized in excel file. Than were transferred and analysis using statistical package SPSS (Windows version). Initially, we calculated the descriptive statistics (means and SDs) of every parameter. The statistical analysis for the comparison between the mean values of every variable was the paired $t$-test, where a high level of significance was adopted ( $p \leq 0.005)$. It was used ANOVA test for pre- post comparison for each variables and then a post hoc analysis using Bonferroni equation. Only those analysis during comparison ( $p \leq 0.005)$ were considered statistically difference for two time measurement. SPSS statistical program was used for calculation of the results obtained from this research study.

\section{Results}

The results from the table 1 show that comparison (pre and post) for Isometric left foot for maximum and average torque is statistical significant different $(p=0.002 ; p=003)$ and showed improvement. The same picture is for the right foot that the results show statistical significant improvement $(p=0.001 ; p=0.002)$ 
Table 1. Pre and post measurement comparison for left and right foot during isometric performance

\begin{tabular}{llcccc}
\hline & & Mean & Std. Deviation & Std. Error & P value \\
\hline Izometri_Left_MaxTor & Pre & 127.75 & 14.975 & 7.4875 & 0.002 \\
& Post & 134.75 & 13.9583 & 7.4792 & \\
Izometri_Left_AvgTor & Total & 131.25 & 14.6593 & 19.325 & \\
& Pre & 106.25 & 15.1959 & 7.598 & 0.003 \\
& Post & 114.25 & 18.5486 & 8.2743 & \\
Izometri_Right_MaxTor & Total & 110.25 & 16.4104 & 6.4086 & \\
& Pre & 143.25 & 18.715 & 9.3575 & 0.001 \\
\hline Izometri_Right_AvgTor & Post & 153.25 & 27.097 & 13.5485 & \\
& Total & 148.25 & 22.2116 & 7.853 & \\
& Pre & 122.25 & 14.0564 & 7.0282 & 0.002 \\
\hline & Post & 135 & 29.9666 & 14.9833 & \\
\hline
\end{tabular}

Data on table 2 show the results from comparison between pre and post training during izokinetic performance test for right foot. Results show significance regarding right foot on extension and flexion performance for average peak torque $(p=0.001 ; p=0.001)$. During this comparison for right foot on peak torque (extension and flexion performance) the results show significance improvement $(p=0.001 ; 0.001)$.

Table 2. Pre and post measurement comparison for right foot during izokinetic performance

\begin{tabular}{llcccc}
\hline & & Mean & Std. Deviation & Std. Error & P value \\
\hline Izokinetic_Right_AvgPeakTor_Extension & Pre & 121 & 43.5737 & 21.7868 & 0.001 \\
& Post & 130.5 & 28.9194 & 14.4597 & \\
& Total & 125.75 & 34.6111 & 12.2369 & \\
Izokinetic_Right_AvgPeakTor_Flexion & Pre & 52.25 & 18.6971 & 9.3486 & 0.001 \\
& Post & 84.5 & 25.8779 & 12.939 & \\
& Total & 68.375 & 27.0921 & 9.5785 & \\
Izokinetic_Right_PeakTor_Extension & Pre & 128.5 & 43.7683 & 21.8842 & 0.001 \\
& Post & 139.25 & 33.6489 & 16.8245 & \\
& Total & 133.875 & 36.596 & 12.9386 & \\
Izokinetic_Right_PeakTor_Flexion & Pre & 57.25 & 20.6781 & 10.339 & 0.001 \\
& Post & 91.25 & 25.3032 & 12.6516 & \\
\hline & Total & 74.25 & 28.0701 & 9.9243 & \\
\hline & & & & &
\end{tabular}

Data on table 3 show comparison results for left foot during izokinetic test (performance) for extension and flexion. Results for comparison on average peak torque (extension) for left foot show no significance improvement while for flexion the results show improvement $(p=0.02)$. Data show that during extension performance peak torque the improvement were no significant while for average peak torque the improvement were significant $(p=0.04)$.

Table 3. Pre and post measurement comparison for left foot during izokinetic performance

\begin{tabular}{llcccc}
\hline & & Mean & Std. Deviation & Std. Error & P value \\
\hline Izokinetic_Left_AvgPeakTor_Extension & Pre & 119.5 & 37.8109 & 18.9055 & NS \\
& Post & 119.75 & 14.3846 & 7.1923 & \\
& Total & 119.625 & 26.4842 & 9.3636 & \\
Izokinetic_Left_AvgPeakTor_Flexion & Pre & 55 & 17.5689 & 8.7845 & 0.021 \\
& Post & 62.25 & 18.4097 & 9.2048 & \\
& Total & 58.625 & 17.1042 & 6.0472 & \\
Izokinetic_Left_PeakTor_Extension & Pre & 126.75 & 39.3732 & 19.6866 & NS \\
& Post & 127.25 & 16.9386 & 8.4693 & \\
\hline \multirow{2}{*}{ Izokinetic_Left_PeakTor_Flexion } & Total & 127 & 28.0612 & 9.9211 & \\
& Pre & 63 & 15.384 & 7.692 & 0.045 \\
\hline & Post & 66.5 & 21.1424 & 10.5712 & \\
\hline
\end{tabular}




\section{Discussion and Conclusion}

Regarding physical components after the intervention data show a significant improvement in strength $(p=0.001)$ for isometric and izokinetic performance on youth basketball players. No significant difference was observed for right foot during izokinetic performance. Most study research have emphasized that strength and power, rather than endurance, should be the main focus of physical conditioning programes for basketball players (Drinkwater et al., 2008; McKeag et al., 2003). Referring to the outcome of the study, when we take a professional basketball athlete who joins in a systematic training program, there is no reason in differentiating prevalent and non prevalent limb, because the workout phase does not lead to such conditions. Other researchers have come to such results too (Bandy et al, 1994; Mohtadi et al., 1990) in examples of normal populations (non-athletes) Knee Force of Professional Basketball Athletes 461 (Davies, 1987), highlevel tennis athletes (Todd et al., 1995), and soccer athletes (Mangine et al., 1990). The same outcome is reached by Holmes and Alderink too (Holmes et al., 1984) operating similar testing velocities throughout an endurance test, whilst Hageman et al. (Hageman et a;.., 1988) came with a similar result with an example of non-athletes. Klopfer and Greij (Klopfer et al., 1988), nevertheless, introduced distinctions between prevalent and non-prevalent limb, using higher elevated speeds during testing action. These outcomes are significant, since the coercion of a wholesome leg in the event of an athletic impairment is a bench mark (Godshall, 1975; Schlinkman, 1984; Todd et al., 1995).

But the results on this study show that we have to perform (to add) more physical fitness exercises during physical training in youth for the nondominant lower limbs (foot). It is known that during shot on the move, basketball players use triple feet movement during shooting performance with the left foot touching the floor before shooting with the right hand (right hand basketball shooters).

Based on the information provided by this study, there is the capacity to establish a training plan that sees the coercion of the wholesome leg as a prescriptive level before the incidence of the athletic impairment (Godshall, 1975; Schlinkman, 1984; Todd et al., 1995)

In basketball, systematic and strenuous training of the sport leads to a major enhance in athletic harms (Apple et al., 1982; Baskiroff, 1990; Ellfeldf et al., 1986). The injuries may affect the ligaments, the muscles, or regarding the bones and can be caused by deficiency of muscle equilibrium between the lower limbs of the player, where the majority of the injuries happens (Mirkin et al., 1985; O Neil et al., 1988; Shambaugh et al., 1991). Being part of a basketball team the professional athlete must improve in continuance fulfilling these two important physical criteria: physical condition and the level of technical ability. The high levels of competition in such a sport demand these elements to be perfected continuously, mainly in professional athletes. This is achieved through energetic, zealous and regular workout. In conclusion, it was found that the fitness training twice weekly could be useful for improving and monitoring training physical parameters in youth basketball players.

\section{References}

Bandy, W.D., K.R. Rusche, and Y. Tekulve (1994). Reliability and limb symmetry for five unilateral functional tests of the lower extremities. Isokinetics Exerc. Sci. 4:108-111.

Baskiroff, B.F (1990). Injuries in Athletics. Thessaloniki, Greece: Salto Publications,

Cabri, J.M (1991). Isokinetic strength of human joints and muscles. Crit. Rev. Biomed. Eng. 19:231-259.

Davies, G.J (1987). A Compendium of Isokinetics in Clinical Usage (3rd ed.). La Crosse, Wl: S. \& S.,.

Godshall, W.R (1975). The predictability of athletic injuries: An eight-year study. J. Sports Med. 3:50-54.

Hageman, P.A., D.M. Gillapsie, and L.D. Hill (1988). Effects of speed and limb dominance on eccentric and concentric isokinetic testing of the knee. J. Orthop. Sports Phys. Ther. 10:59-65

Holmes, J.R., and G.J. Alderink (1984). Strength characteristics of the quadriceps femoris and hamstring muscles in high school students. Phys. Ther. 64:914-918.

Ellfeldf, H.J., and J.G. Yost JR (1986). The lower extremity and spine in sports medicine. In: Basketball Injuries. St. Louis: Mosby Publishing, 1986. pp. 1440-1466.

Klopfer, D.A., and S.D. Greij (1988). Examining quadriceps/hamstring performance at high velocity isokinetics in untrained subjects. J. Orthop. Sports Phys. Ther. 10:18-22.

Knapik, J.J., and M.U. Ramos (1980). Isokinetic and isometric torque relationships in the human body. Arch. Phys. Med. Rehabil. 61: 64-67.

Keasays SL, Bullock SJ and Keasys AC (2000). Strength and function before and after anterior cruciate ligament reconstruction. Clinical orthopedics and related research (373): 174-183

Mangine, R.E., F.R. Noyes, M.P. Mullen, and S.D. Barber (1990). A physiological profile of the elite soccer athlete. J. Orthop. Sports Phys. Ther. 12:147-152.

Mirkin, G., and M. Hoffman (1985). Athletiatrics. Parisianos, Athens: Scientific Publications, 
Mohtadi, N.G., G.N. Kiefer, T.K. Ford, and S. Watters (1990). Concentric and eccentric quadriceps torque in pre-adolescent males. Can. J. Sport Sci. 15:240-243.

Nicholas, J J (1989). Isokinetic testing in young non athletic able bodied subjects . Arch Phys Med Rehabil.,70:210-215.

Jarani, J. Ushtelenca K and Spahi A (2014). The current level of health and skills related fitness indicators in Albanian children; reference values from a country in transition, Faculty of Kinesiology University of Zagreb 1, 264-268.

Jarani, J. Grontved. A, Muca. F, Spahi. A, Qefalia. D, Ushtelenca K et al., (2015). Effects of two physical education programs on healthand skill related physical fitness of Albanian children. Journal of Sports Sciences; in process

doi:10.1080/02640414.2015.1031161

O'Neil, B.D., and L. Micheli (1988). Overuse injuries in the young athlete. Clin. Sports Med. 7:591-600.

Sschilnkman, B (1984). Norms for high school football players derived from Cybex data reduction computer. J. Orthop. Sports Phys. Ther. 5:243-245.

Stocker, B.D., J. Nyland, and D.N. Caborn (1996). Concentric isokinetic knee torque characteristics of female volleyball athletes. Isokinetics Exerc. Sci. 5:111-114.

Shambaugh, J.P., K.K. Klein, and H.J. Hembert (1991). Structural measures as predictors of injury in basketball players. Med. Sci. Sports Exerc. 23:522-527..

Todd, S., E. Ellenbecker, and P. Roetert (1995). Concentric isokinetic quadriceps and hamstring strength in elite junior tennis players. Isokinetics Exerc. Sci. 5:3-6.

Alexander, M.J., and G.E. Molnan (1973). Muscular strength in children: Preliminary report on objective standards. Arch. Phys.Med. Rehabil. 54:424-427.

Apple, F.D., M.S. O'Toole, and A. Corey (1982). Professional basketball injuries. Phys. Sports medicine 10:81-86.

Walmsley, R.P (1996). Pitfalls in isokinetics. Isokinetics Sci. Exerc. 5: 127-129. 
